\title{
Use of Pyrosequencing to Quantify Incidence of a Specific Aspergillus flavus Strain Within Complex Fungal Communities Associated with Commercial Cotton Crops
}

\author{
Modan K. Das, Kenneth C. Ehrlich, and Peter J. Cotty
}

First and third authors: Agricultural Research Service, United States Department of Agriculture, Department of Plant Sciences, University of Arizona, Tucson 85721-0036; and second author: Agricultural Research Service, United States Department of Agriculture, New Orleans. Accepted for publication 25 September 2007.

\begin{abstract}
Das, M. K., Ehrlich, K. C., and Cotty, P. J. 2008. Use of pyrosequencing to quantify incidence of a specific Aspergillus flavus strain within complex fungal communities associated with commercial cotton crops. Phytopathology 98:282-288.

Atoxigenic strains of Aspergillus flavus have been used as aflatoxin management tools on over 50,000 hectares of commercial crops since 2000. To assess treatment efficacy, atoxigenic strain incidence is routinely monitored by vegetative compatibility analyses (VCA) that require culturing, generation of auxotrophs, and complementation with tester mutants. Two pyrosequencing assays (PA) that require no culturing were developed for monitoring incidences of atoxigenic strains on ginned cottonseed. The assays, which quantify frequencies of characteristic single nucleotide polymorphisms (SNPs) in the aflR and $p k s A$ genes, were validated against standard VCA on cottonseed collected from commercial gins in South Texas, Arizona, and Southern California where the atoxigenic strain AF36 is used to manage aflatoxin contamination. Cottonseed washings were subjected to both VCA and PA. PA was performed
\end{abstract}

ABSTRACT directly on DNA isolated from particulates pelleted from the wash water by centrifugation. Addition of $\mathrm{CaCl}_{2}$ and diatomaceous earth prior to pelleting increased the amount of DNA isolated. Accuracy and reproducibility of the PA were contrasted with those for the VCA that has been used for over a decade. Correlation coefficients between VCA and PA indicated good correspondence between the results from the two assays $(\mathrm{r}=0.91$ for $a f l R$ assay and $\mathrm{r}=0.80$ for $p k s A$ assay). PAs were highly variable for samples with low incidences of $A$. flavus due to variability in the initial polymerase chain reaction step. This held for both DNA isolated from cottonseed washes and for mixtures of purified DNA. For samples yielding low quantities of A. flavus DNA, averaging of results from 4 to 5 replicates was required to achieve acceptable correlations with VCA. Pyrosequencing has the potential to become a powerful tool for monitoring atoxigenic strains within complex A. flavus communities without limitations imposed by traditional culturing methods.

Additional keywords: biocontrol, population genetics.
Aflatoxins are highly toxic carcinogens produced by several species of Aspergillus. Presence of aflatoxins in human foods causes chronic health effects including immune system suppression, growth retardation, cancer, and death if ingested at high concentrations $(23,33)$. Health concerns have led to regulatory limitations on the quantity of aflatoxins permitted in foods and feeds throughout most of the world (32). Although aflatoxin contamination has been a serious concern for several important United States crops for three decades, extensive research programs directed at developing resistant crop varieties and cultural management practices have failed to produce management tools sufficient to meet industry needs (29). This has resulted in increased interest in utilizing atoxigenic strains of Aspergillus flavus to manage contamination.

A. flavus is the most important causal agent of aflatoxin contamination. However, this fungal species is highly variable in aflatoxin-producing ability. Many strains of A. flavus do not produce aflatoxins and are termed atoxigenic. Certain atoxigenic strains are used to competitively exclude aflatoxin producers and, in so doing, to reduce the aflatoxin content of crops. Atoxigenic strain applications seek to cause both single season and long-term changes to the composition of fungal communities and, in so

Corresponding author: P. J. Cotty; E-mail address: pjcotty@email.arizona.edu

doi:10.1094/PHYTO-98-3-0282

This article is in the public domain and not copyrightable. It may be freely reprinted with customary crediting of the source. The American Phytopathological Society, 2008. doing, reduce the aflatoxin-producing potential of those communities (9-13). Several atoxigenic strains of A. flavus are currently being used to reduce crop aflatoxin contamination through competitive exclusion of aflatoxin producers $(4,8)$. Since the year 2000, over 50,000 hectares of commercial cotton have been treated with one of these atoxigenic strains, AF36, in order to manage aflatoxin contamination of cottonseed in Arizona, Texas, and California. AF36 occurs on cotton in these areas naturally making up on average $4 \%$ of the A. flavus community on cottonseed after ginning. To assess treatment efficacy and residual influences of treatments, atoxigenic strain incidence is routinely monitored by vegetative compatibility analyses (VCA). Such monitoring is also required for the pesticide registration process.

A. flavus is a filamentous fungus with no known sexual stage. However, like many fungi, A. flavus has a vegetative incompatibility system that limits gene flow among dissimilar individuals. This vegetative incompatibility system divides A. flavus into numerous vegetative compatibility groups (VCGs) which reproduce and disperse in primarily a clonal manner. All members of the VCG to which AF36 belongs lack the ability to produce aflatoxins. VCA determine if an isolate is a clone of AF36 by determining if that isolate belongs to the same VCG as AF36. This requires fungal isolation, culturing, generation of auxotrophs, and complementation with tester mutants $(5,14)$. Over 10,000 VCA per year are performed by industry and public sector laboratories in order to monitor efficacy of treatments and assist with development of management strategies based on atoxigenic strains. 
Pyrosequencing (Biotage, Uppsala, Sweden) is a method developed relatively recently for sequencing short segments of DNA (50 to 70 nucleotides). It is capable of simultaneously sequencing 96 different templates $(2,19,31)$. Pyrosequencing has the potential advantages of accuracy, flexibility, parallel processing, and can be easily automated. The methodological performance of pyrosequencing in determination of difficult secondary DNA structures (30) mutation detection (3), cDNA analysis (28), resequencing of disease associated genes (20), bacterial typing (27), viral typing (21), and single nucleotide polymorphism (SNP) analysis $(2,19)$ has been shown. It has also been used in the detection and identification of fungi that are pathogenic to humans (22).

In A. flavus, the 25 or more genes coding for the enzymes and regulatory proteins involved in aflatoxin biosynthesis are contained in a 66-kb cluster (18). Gene order and many of the genes are highly conserved among most of the aflatoxin-producing species (18). The entire gene cluster sequences of the atoxigenic A. flavus AF36 and those of several aflatoxin-producing fungi have been reported (18). The basis for atoxigenicity in AF36 is a single nucleotide polymorphism that inserts a stop codon near the beginning of the coding sequence ( $p k s A$ ) for the polyketide synthase. Although SNPs are common, AF36 contains all genes in the aflatoxin biosynthesis cluster that aflatoxin-producing A. flavus contain with all gene sequences highly conserved (homology $>90 \%)(18)$.

The present study sought to assess the potential of using pyrosequencing to assay individual fungal strains in complex fungal communities without the need for culturing. During the process, methods were developed for monitoring both the incidence of the atoxigenic A. flavus strain AF36 based on a characteristic SNP in the aflatoxin cluster $a f l R$ gene and for monitoring atoxigenicity based on incidence of SNP in the pksA gene that causes AF36 to be unable to make aflatoxins.

\section{MATERIALS AND METHODS}

Cottonseed samples and fungal isolates. Initial assay development utilized the DNeasy Plant DNA Mini Kit (Qiagen, Valencia, CA) to isolate DNA from axenic cultures of atoxigenic A. flavus AF36 (ATCC 96045) and the aflatoxin-producing isolate AF70 (ATCC MYA384) belonging to the S morphotype (10) of A. flavus. Additional tests were performed with spores from these isolates cultured on 5:2 agar (5\% V-8, 2\% agar, pH 5.2) medium. Active cultures were maintained on $5: 2$ agar in darkness at $31^{\circ} \mathrm{C}$. For long-term storage, plugs of sporulating cultures were maintained in sterile water at 4 to $8^{\circ} \mathrm{C}$ as previously described (10). Cottonseed samples were obtained from commercial gins in Arizona, California, and Texas in areas where growers utilize AF36 to manage aflatoxin contamination of cottonseed in 2003 (17 total) and 2004 (9 total). Dry cottonseed samples (4 to $7 \mathrm{~kg}$ ) were shipped directly to our laboratory and stored in a moisture proof container at room temperature $\left(22\right.$ to $\left.24^{\circ} \mathrm{C}\right)$ until analyzed.

Pelleting spores from cottonseed washes. Cottonseed (25 g) was washed in $500 \mathrm{ml}$ of sterile water containing $10 \mu \mathrm{g}$ of Tween 80 in a 1-liter media bottle by shaking vigorously (shaker model HS 501, IKA, Wilmington, NC) at $220 \mathrm{rpm}$ for $20 \mathrm{~min}$. Washings were passed through sterile cheese cloth to remove large particulates. Fungal spores and other small particulates were pelleted from the washings by centrifugation. Additives for more efficient pelleting of spores and thus DNA yield from washings were tested. Varying amounts of $\mathrm{CaCl}_{2}$ and diatomaceous earth (DE) were added to washings prior to centrifugation $(10,000 \times g)$ for $20 \mathrm{~min}$. DNA was isolated from the pellet and quantified. In the first test, the four treatments used were control (zero $\mathrm{CaCl}_{2}$ and zero DE), $250 \mathrm{mM} \mathrm{CaCl}_{2}, 0.2 \%$ (wt/vol) $\mathrm{DE}$, and $250 \mathrm{mM} \mathrm{CaCl}_{2}$ with $0.2 \%$ (wt/vol) DE. In the second test, the treatments were $250 \mathrm{mM} \mathrm{CaCl} 2,250 \mathrm{mM} \mathrm{CaCl} 2+0.2 \%$ (wt/vol) DE, $250 \mathrm{mM}$ $\mathrm{CaCl}_{2}+0.1 \%$ (wt/vol) $\mathrm{DE}$, and $250 \mathrm{mM} \mathrm{CaCl} 2+0.05 \%$ (wt/vol)
DE. In the third test, the treatments were $500 \mathrm{mM} \mathrm{CaCl}_{2}+0.05 \%$ (wt/vol) DE, $250 \mathrm{mM} \mathrm{CaCl} 2+0.05 \%$ (wt/vol) DE, $125 \mathrm{mM}$ $\mathrm{CaCl}_{2}+0.05 \%$ (wt/vol) DE, and only $0.05 \%$ (wt/vol) DE. The first and the second tests were performed thrice while the third test was performed twice.

DNA isolation. Cottonseed wash water $(45 \mathrm{ml})$ was poured into a $50-\mathrm{ml}$ polypropylene conical tube, $\mathrm{CaCl}_{2}$ (final concentration, $250 \mathrm{mM}$ ) and DE (final concentration, $0.05 \% \mathrm{wt} / \mathrm{vol}$ ) were added and centrifuged at $10,000 \times g$ for $20 \mathrm{~min}$. The pellet was resuspended in $500 \mu \mathrm{l}$ of water and transferred to $1.5-\mathrm{ml}$ microfuge tube. One hundred microliters of unwashed, 106 micron and finer glass beads (Sigma, St. Louis, MO) was added to the suspension, centrifuged at $14,000 \mathrm{rpm}$ for $5 \mathrm{~min}$, the supernatant was discarded, and the pellet was kept. DNA was isolated using Qiagen Plant DNA Mini Kit with minor modifications. After adding 400 $\mu \mathrm{l}$ of buffer AP1 and $4 \mu \mathrm{l}$ of RNase A from the kit to the pellet, the suspension was vortexed vigorously for $1 \mathrm{~min}$ to break up fungal material. The resulting suspension was incubated $\left(65^{\circ} \mathrm{C}, 30 \mathrm{~min}\right)$ after addition of Proteinase K (400 $\mu \mathrm{g}$, Fermentas, Hanover, MD). During incubation, the sample was mixed three times at regular intervals by inverting the tube. From some of the samples, DNA was isolated with FastDNA SPIN Kit according to manufacturer's instructions (Qbiogene, Irvine, CA). DNA concentration was estimated from absorbance at $260 \mathrm{~nm}$ and purity estimated from A260/A280 ratios.

Amplification of target DNA. Two rounds of polymerase chain reaction (PCR) were performed on DNA isolated from cottonseed washes; the first was to amplify the desired A. flavus sequence from the mixed environmental DNA and the second to label target sequence with biotin for subsequent pyrosequencing. For the aflR gene the first PCR primers were: 5'-GGAAACAAGTCTTTTCTGG-3' and 5'-GCGAGTCTGGGAGGAACG-3', (expected amplicon, $432 \mathrm{bp}$ ) and the second PCR primers (expected amplicon, $139 \mathrm{bp}$ ) were: 5'-TCACGCAGTTCTCTGGTCAC-3' and 5'-GTTGCCTCGCACTTAGACCT-3'. For the $p k s A$ gene the first primer set was: 5'-GCTGGGATTCTGCATGGGTT-3' and 5'-CCATCTGAGGCATCGCACA-3' (amplicon, $421 \mathrm{bp}$ ), and the second primer set was: 5'-TGTAGCGATGATCGAGGTGA-3' and 5'-TGTGGTCCGACAGAACACTT-3' (amplicon, $97 \mathrm{bp}$ ). The reverse primer of the second primer set was 5 '-biotinylated and high-performance liquid chromatography (HPLC)-purified. PCR for the first round of amplification used a HotMaster PCR kit (Eppendorf, Westbury, NY). The 50- $\mu$ l reaction mixture included $3 \mu \mathrm{l}$ of DNA $(5 \mathrm{ng} / \mu \mathrm{l}), 5 \mu \mathrm{l}$ of $10 \times$ PCR buffer, $1 \mu \mathrm{l}$ of $10 \mathrm{mM}$ dNTPs, $1.2 \mu \mathrm{l}(10 \mathrm{ng} / \mu \mathrm{l})$ of each primer, $0.3 \mu \mathrm{l}$ of Taq polymerase, and $38.3 \mu \mathrm{l}$ of deionized water. Since the proportion of DNA composed of A. flavus DNA was unknown, PCR was also conducted with different concentrations of DNA templates for the same sample as follows: 20, 10, 6, 1.25, and $0.25 \mu \mathrm{l}$, regardless of sample DNA concentration. PCR conditions were: $5 \mathrm{~min}$ at $95^{\circ} \mathrm{C}$ followed by 35 cycles at $95^{\circ} \mathrm{C}$ for $20 \mathrm{~s}, 46.6^{\circ} \mathrm{C}$ (for $a f l R$ ), or $58^{\circ} \mathrm{C}$ (for $p k s A$ ) for $20 \mathrm{~s}, 72^{\circ} \mathrm{C}$ for $30 \mathrm{~s}$. A final extension was conducted for $10 \mathrm{~min}$ at $72^{\circ} \mathrm{C}$. Amplicons were visualized with SYBR Gold after $1.2 \%$ agarose gel electrophoresis.

Amplicon visualization after electrophoresis was used to determine the quantity of PCR products used for amplification of the inner segments. Amplicons with prominent, thick bands were diluted 10 times and those with faint, thin bands or absent bands were not diluted. PCR for the second round of amplification used AmpliTaq Gold DNA Polymerase, LD PCR kit (Applied Biosystems, Foster City, CA). The 50- $\mu$ l reaction mixture included either $3 \mu$ of PCR product from the first round of amplification or 1 to 10 diluted PCR product, $5 \mu \mathrm{l}$ of $10 \times$ PCR buffer, $2 \mu \mathrm{l}$ of $\mathrm{MgCl}_{2}$ for aflR and $3 \mu \mathrm{l}$ of $\mathrm{MgCl}_{2}$ for $p k s A$ assay, $1 \mu \mathrm{l}$ of $10 \mathrm{mM}$ dNTPs, $1.2 \mu \mathrm{l}(10 \mathrm{ng} / \mu \mathrm{l})$ of each primer, $0.25 \mu \mathrm{l}$ of Taq polymerase, and 36.3 and $35.35 \mu \mathrm{l}$ of deionized water for aflR and $p k s A$ assays, respectively. PCR conditions were the same as for the first 
amplification except that the annealing temperatures for aftR and pksA assays were 56 and $61^{\circ} \mathrm{C}$, respectively, and 48 cycles were run in order to completely incorporate the biotinylated primers.

Template preparation for pyrosequencing. Biotinylated PCR products were transferred to a new PCR plate with $3 \mu \mathrm{l}$ of streptavidin Sepharose beads (Amersham Biosciences AB, Uppsala, Sweden) and $40 \mu \mathrm{l}$ of binding buffer (Biotage, Uppsala, Sweden) per reaction. The PCR plate was sealed and shaken at $1,400 \mathrm{rpm}$ for $10 \mathrm{~min}$ at room temperature $\left(22\right.$ to $\left.24^{\circ} \mathrm{C}\right)$. During shaking, biotinylated PCR products were immobilized onto the streptavidin Sepharose beads. The sequencing plate was prepared as follows. Sequencing primer $(0.2 \mu \mathrm{l}, 100 \mu \mathrm{M})$ and $40 \mu \mathrm{l}$ of annealing buffer were added to each well of a sequencing plate (PSQ low plate, Biotage, Uppsala, Sweden). PCR products immobilized on the streptavidin Sepharose beads were transferred to the sequencing plate using a Vacuum Prep Tool following manufacturer's protocols (Biotage). During this process the beads containing immobilized PCR products were captured on the filter probes of the Vacuum Prep Tool, washed with 70\% ethanol (10 s), denatured in $0.2 \mathrm{M} \mathrm{NaOH}$ (10 s) to obtain single-stranded DNA, and washed in washing buffer (10 mM Tris-Acetate, $\mathrm{pH} 7.6$ ) (10 s). The washed beads coated with single-stranded DNA were released into the sequencing plate. To hybridize the sequencing primer to the single-stranded DNA template, plates were heated to $90^{\circ} \mathrm{C}$ for $5 \mathrm{~min}$, using the PSQ 96 MA Sample Prep Thermoplate Kit (Biotage). The sequencing plate was kept on the thermoplate for $5 \mathrm{~min}$ after it was removed from the heating block and finally cooled to room temperature for $10 \mathrm{~min}$. The sequencing primers for aflR and $p k s A$ assays were 5'-AACGCACAGCTAGACAAT-3' and 5'-TTGGTCTACCATTGTTTG-3', respectively.

Pyrosequencing and data analysis. The 96-well plate containing single-stranded DNA template with the annealed sequencing primer was placed inside the pyrosequencing instrument PSQ 96 MA (Biotage). The PSQ 96 MA cartridge was filled with an enzyme mixture (DNA polymerase, ATP-sulfurylase, luciferase, and apyrase), a substrate mixture (luciferin, adenosine 5'-phosphosulfate), and nucleotides (dATP, dCTP, dGTP, and dTTP) contained in PSQ 96 SNP Reagent Kit $5 \times 96$ (Biotage). PSQ 96 MA SNP software v2.0 was used to calculate reagent quantities required for each assay and to analyze genotypes.

Effect of low concentration of DNA on PCR and pyrosequencing. Quantities of DNA isolated from the cottonseed washings were low (1.5 to $100 \mathrm{ng} / \mu \mathrm{l})$ and the proportion of DNA originating from A. flavus was unknown. In order to assess influences of low concentrations of A. flavus DNA on variability in pyrosequencing results, pyrosequencing was performed on constructed DNA mixtures subjected to serial dilutions. DNA isolated from cultures of AF36 and AF70 were mixed in four proportions (90:10, 60:40, 50:50, and 30:70 of AF36/AF70). For amplification of the outer segment, the DNA mixtures were used in the fol- lowing quantities for reaction: 150, 15, 1.5, 0.15, 0.015, 0.0015, 0.0003 , and $0.00006 \mathrm{ng}$. The amplification of the inner segment and pyrosequencing were done as described above. Each DNA mixture was investigated at separate times as a distinct test with four replicates.

VCA. Incidence of the atoxigenic biocontrol strain AF36 on all commercial cottonseed lots was determined by VCA, following the protocols used to assess the incidence of AF36 on crops treated in aflatoxin management programs (4). Cottonseed (25 g) was washed as described earlier. Isolates were recovered by a dilution plate technique on a semi-selective rose Bengal agar as previously described $(13,14)$. For each analysis, isolations were performed on each sample at least twice until 15 isolates were recovered. No more than eight isolates were recovered from a single washing. The incidence of AF36 among the 15 isolates was determined with VCA following previously described protocols $(5,13)$. VCA analyses required selection of nitrate nonutilizing auxotrophs for each isolate and subsequent pairing of the auxotrophs with complementary tester mutants previously generated from AF36 (14). If the isolate belongs to the same VCG as AF36, then prototrophic growth occurs where mycelia of tester and isolate auxotrophs grow together. Auxotrophs were generated on SEL agar (Czapek-Dox broth [Difco] with $25 \mathrm{~g}$ of $\mathrm{KClO}_{3}$ per liter, $50 \mathrm{mg}$ of rose Bengal per liter and $20 \mathrm{~g}$ of agar per liter, $\mathrm{pH}$ 7.0) as previously described (13). Briefly, for each isolate, $15 \mu \mathrm{l}$ of a spore suspension was seeded into wells $(3 \mathrm{~mm})$ cut into the center of a petri dish's SEL agar. Auxotrophs formed spontaneously during incubation at $31^{\circ} \mathrm{C}$. Auxotrophic sectors were transferred to MIT (Czapek-Dox broth with $15 \mathrm{~g}$ of $\mathrm{KClO}_{3}$ per liter and $20 \mathrm{~g}$ of agar per liter, $\mathrm{pH} 6.5$ ) for 3 to 5 days, at $31^{\circ} \mathrm{C}$, in order to stabilize the mutants. Mutants were subsequently grown on 5:2 agar and stored in sterile water, as described above, until used in complementation tests.

Assignments of isolates to the VCG of AF36 were made on the basis of complementation tests (6) between $\mathrm{NiaD}^{-}$(deficient in the structural gene for nitrate reductase) and cnx (deficient in a molybdenum cofactor) tester mutants (characterized by the method of Cove) (16) of AF36 and an uncharacterized nit mutant of the isolate to be assigned. One complementation test was performed on each petri dish. Three wells (3- $\mathrm{mm}$ in diameter), $1 \mathrm{~cm}$ apart, were cut in a triangular pattern in the center of a $10-\mathrm{cm}$ plastic petri dish containing 20 to $25 \mathrm{ml}$ of medium. The complementation medium consisted of Czapek-Dox broth adjusted to $\mathrm{pH}$ 6.0 with $2 \mathrm{~N} \mathrm{HCl}$, solidified with $2 \%$ agar (Bacto-Agar, Difco), and supplemented with the micronutrients as described by Adye and Matales (1). For each complementation test, one well each was seeded with the AF36 tester mutants and one isolate mutant. Reactions between auxotrophs were evaluated after 5 and 10 days at $32^{\circ} \mathrm{C}$. For each 2003 crop sample, the complete VCA was performed once; for each 2004 sample, VCA was performed six times.

TABLE 1. Quantity of total DNA (ng) isolated from cottonseed washings containing diatomaceous earth (DE) and/or calcium chloride

\begin{tabular}{|c|c|c|c|}
\hline Test & Treatments & Mean $^{z}$ & SD \\
\hline Test 1 & $\begin{array}{l}\text { No } \mathrm{CaCl}_{2}, \mathrm{No} \mathrm{DE} \\
250 \mathrm{mM} \mathrm{CaCl} \\
0.2 \%, \mathrm{wt} / \mathrm{vol}, \mathrm{DE} \\
250 \mathrm{mM} \mathrm{CaCl}{ }_{2}+0.2 \%, \mathrm{wt} / \mathrm{vol}, \mathrm{DE}\end{array}$ & $\begin{array}{r}143 \mathrm{~b} \\
361 \mathrm{~b} \\
420 \mathrm{~b} \\
1,623 \mathrm{a}\end{array}$ & $\begin{array}{l}1.5 \\
2.4 \\
3.3 \\
2.6\end{array}$ \\
\hline Test 2 & $\begin{array}{l}250 \mathrm{mM} \mathrm{CaCl}_{2} \\
250 \mathrm{mM} \mathrm{CaCl}_{2}+0.2 \%, \mathrm{wt} / \mathrm{vol}, \mathrm{DE} \\
250 \mathrm{mM} \mathrm{CaCl}_{2}+0.1 \%, \mathrm{wt} / \mathrm{vol}, \mathrm{DE} \\
250 \mathrm{mM} \mathrm{CaCl}_{2}+0.05 \%, \mathrm{wt} / \mathrm{vol}, \mathrm{DE}\end{array}$ & $\begin{array}{r}497 \mathrm{~b} \\
1,227 \mathrm{a} \\
1,040 \mathrm{a} \\
1,207 \mathrm{a}\end{array}$ & $\begin{array}{l}4.4 \\
4.5 \\
3.9 \\
6.6\end{array}$ \\
\hline
\end{tabular}

\footnotetext{
${ }^{\mathrm{z}}$ Mean of three replications for tests 1 and 2, and two replications for test 3.Values followed by a common letter are not significantly different as indicated by a
} least significant difference test at $P=0.05$. 


\section{RESULTS}

DNA recovery from cottonseed washes. Addition of $\mathrm{CaCl}_{2}$ and/or DE to cottonseed wash water resulted in increased DNA recovery (Table 1). The DE also permitted easy visualization of the pelleted particulates after centrifugation. Optimal DNA recovery was achieved by the addition of $250 \mathrm{mM} \mathrm{CaCl}_{2}$ and $0.05 \%$, wt/vol, DE.

Pyrosequencing accuracy. The accuracy of pyrosequencing in determining proportions of the target SNPs in DNA mixtures was confirmed by performing the pyrosequencing assays (PA) on purified DNAs from AF36 and AF70 isolates mixed in different ratios. Results of both aflR and $p k s A$ PAs were highly correlated with the percent AF36 in the sample subjected to the PAs $(\mathrm{r}=$ $0.997, P<0.01$ for aflR assay and $\mathrm{r}=0.999, P<0.01$ for $p k s A$ assay; Fig. 1). The standard deviation (SD) of the mean for these tests included pipetting error and ranged from 0.0 to 6.8 . In a separate set of tests involving both aflR and $p k s A$ PAs, DNA from AF36 and AF70 were allocated into four replications after mixing. Thus, the SD from these later tests did not include pipetting error and remained low (0.9 to 3.6). These two set of tests demonstrate the high reproducibility and high precision of pyrosequencing.

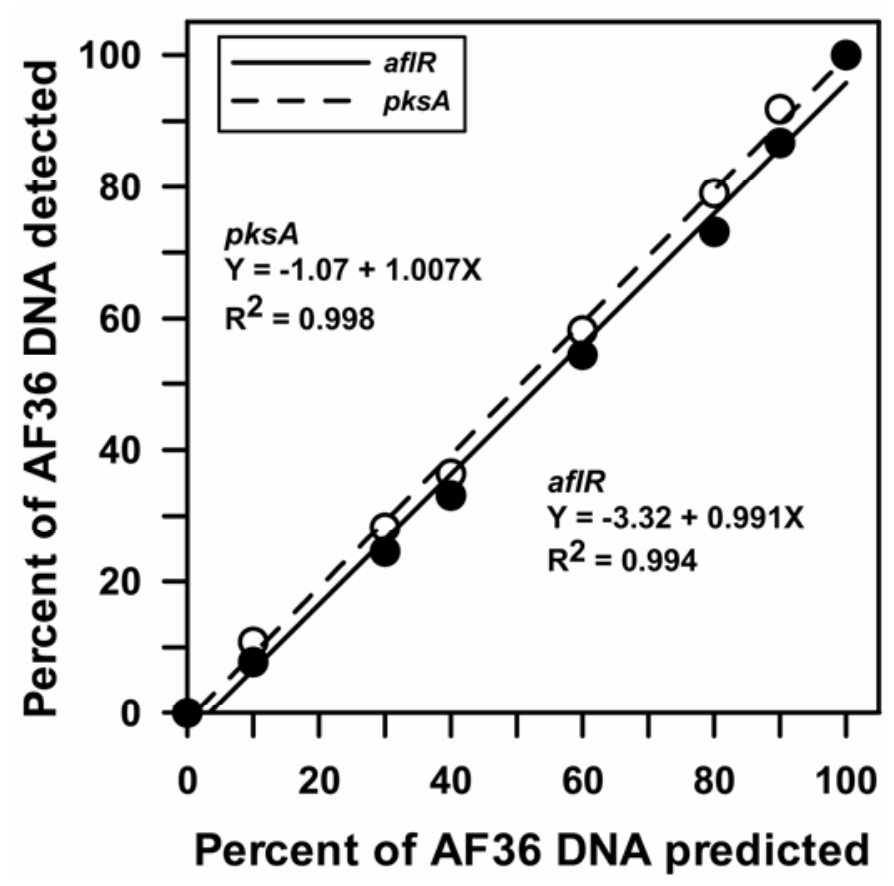

Fig. 1. Proportion of Aspergillus flavus strain AF36 DNA detected by pyrosequencing versus predicted proportion.
Precision of VCA. Variation among multiple VCA on the same sample includes both sampling error and error of the VCA itself. The SD of the VCA ranged from 3 to 59\% with the SD increasing with decreased mean (Table 2). Thus, the VCA was more precise for samples with high incidence of AF36.

Comparison of VCA and pyrosequencing for quantifying incidence of AF36. For the 2004 crop samples, mean values of percent AF36 quantified by VCA were, in general, highly correlated with those of the pyrosequencing methods $(\mathrm{r}=0.91$ for aflR assay and $\mathrm{r}=0.80$ for $p k s A$ assay) (Table 3). For the 2003 crop samples, both pyrosequencing and VCA were performed once on each cottonseed sample and correlation coefficients between percent AF36 quantified by the two methods were also high ( $\mathrm{r}=0.76$ for aflR assay and $\mathrm{r}=0.65$ for $p k s A$ assay) (Table 3).

Effect of low quantities of target DNA on PCR and pyrosequencing. The concentration of target DNA influenced the SDs of the PAs. Serial dilution of DNA mixtures prior to the application of pyrosequencing consistently resulted in increased assay variance at low DNA concentrations. In four independent tests with four replicates the mean values for percent AF36 quantified by pyrosequencing were very similar to expected values, except for the reactions where template DNA amounts were $0.0003 \mathrm{ng}$ or less (Table 4). These levels were near the minimum required for successful PCR under our conditions as exemplified by failure to obtain detectable amplicons when template DNA was at similar concentrations. In general, SDs were higher (as high as 57.7 for some samples) when the amount of DNA used in the first PCR was $0.0015 \mathrm{ng}$ and lower (Table 4). High negative correlations were observed between template concentration and assay SD in each of the four tests $(\mathrm{r}=-0.68,-0.79,-0.77$, and -0.72 for tests $1,2,3$, and 4, respectively). Mean SDs across tests differed significantly $(P<0.01)$ among DNA concentrations with assays performed with $0.0003 \mathrm{ng}$ of template DNA having the highest SD (Table 4).

Variability resulting from first PCR. Pyrosequencing itself proved to have very low variability (Fig. 1). However, the PAs frequently had considerable variability. Repeated PCR of the DNA from the same cottonseed wash revealed that the variability was attributable to the first PCR. The complete pyrosequencing

TABLE 3. Correlation between mean percent Aspergillus flavus AF36 quantified by pyrosequencing assays (PA) and vegetative compatibility analyses (VCA) for the 2003 and 2004 crops

\begin{tabular}{lll}
\hline & \multicolumn{2}{c}{ VCA } \\
\cline { 2 - 3 } PA & 2003 & 2004 \\
\hline aflR & $0.76^{* * z}$ & $0.91^{* *}$ \\
pksA & $0.65^{* *}$ & $0.80^{* *}$ \\
\hline $\mathrm{z} * *$ indicates Pearson's product moment correlation is significant at $P \leq 0.01$.
\end{tabular}

TABLE 2. Mean and standard deviation (SD) of percent Aspergillus flavus AF36 from vegetative compatibility analyses (VCA), and from two pyrosequencing assays ( $a f l R$ and $p k s A$ ) for nine cottonseed samples from 2004 crops

\begin{tabular}{|c|c|c|c|c|c|c|}
\hline \multirow[b]{2}{*}{ Sample ID } & \multicolumn{2}{|c|}{$\mathrm{VCA}^{\mathrm{y}}$} & \multicolumn{2}{|c|}{$a f l R$ assay $^{z}$} & \multicolumn{2}{|c|}{$p k s A$ assay $^{z}$} \\
\hline & Mean & $\mathrm{SD}$ & Mean & $\mathrm{SD}$ & Mean & SD \\
\hline B3 & 93.3 & 4.2 & 98.8 & 3.0 & 89.9 & 10.3 \\
\hline B4 & 87.8 & 10.7 & 87.7 & 17.7 & 96.7 & 7.1 \\
\hline C60 & 98.9 & 2.7 & 73.0 & 25.8 & 95.7 & 5.3 \\
\hline B1 & 42.9 & 10.1 & 46.7 & 33.6 & 50.7 & 40.6 \\
\hline B16 & 38.4 & 18.9 & 22.3 & 22.3 & 59.1 & 32.9 \\
\hline $\mathrm{C} 22$ & 31.1 & 10.9 & 46.0 & 14.6 & 78.8 & 19.8 \\
\hline B9 & 31.9 & 16.9 & 27.0 & 21.4 & 63.3 & 41.7 \\
\hline B5 & 29.3 & 8.4 & 36.1 & 9.9 & 62.1 & 38.1 \\
\hline $\mathrm{C} 83$ & 23.4 & 13.8 & 28.6 & 10.5 & 22.1 & 11.6 \\
\hline
\end{tabular}

y VCA were performed six times for each sample.

z Pyrosequencing were performed 6 to 10 times for aflR assay and 5 to 13 times for $p k s A$ assay. 
assay was applied three times independently to the same DNA sample isolated from a cottonseed wash. For this test, cottonseed washes with low concentrations of target A. flavus DNA were selected. In addition, the second PCR and subsequent pyrosequencing was applied three times to the products from each initial PCR. The average SD for the complete assay was over 65-fold higher than that for assays when the amplicon from the first PCR was held constant $(P<0.01$, Table 5).

\section{DISCUSSION}

Atoxigenic strains of $A$. flavus have been used on over 50,000 ha of commercial crops since 2000 as aflatoxin management tools. The use of atoxigenic strains of A. flavus as biological control agents in the management of aflatoxin contamination seeks to modify the average aflatoxin-producing potential of $A$. flavus communities by increasing incidences of atoxigenic strains. The biological control strains are distinct VCGs and VCAs are useful for monitoring incidences of the atoxigenic strains of A. flavus on crops and in the environment. The atoxigenic strain of A. flavus AF36 is applied to cotton fields of Arizona and Texas and routinely monitored by VCA (15). Such monitoring is required to assess both efficacy and long-term influences of treatment in order to optimize the technology and to meet ecological questions raised during the registration of such agents as biopesticides. VCA have several drawbacks. VCA requires isolation and culturing of individuals from fungal communities prior to subjecting each isolate to mutant selection and subsequent pairing with auxotroph testers. The isolation process is associated with a sampling error influenced by the number of isolates examined. A quantity limited by cost, labor and space. This limitation is shared with several DNA based techniques including fingerprinting $(25,26)$. VCA are also fairly expensive requiring, with current protocols, culture of 12 to 15 isolates, and use of over 65 dishes of culture media, per crop sample. VCA also require considerable time, often a month or longer to fully complete an analysis. This can frustrate those utilizing atoxigenic strain technologies and wishing rapid assessment of application efficacy.
In the current study, pyrosequencing has been shown to be a viable alternative to VCA that does not require culturing. The pyrosequencing protocols outlined here provide improvements over VCA in all the aspects listed above. Because culturing is not required, sampling errors associated with typing only a few cultured isolates are reduced by extracting DNA from many individuals simultaneously. In addition, no culture dishes or media are required, resulting in considerable savings in laboratory supplies, labor, and incubator/refrigerator space. Furthermore, unlike VCA that require isolations, selection of spontaneous mutants, and complementation with tester auxotrophs, pyrosequencing can be performed on numerous samples in a single day. However, although the individual assay costs of expendables and labor for PAs are far lower than those for VCA, pyrosequencing requires a substantial initial capital outlay that may prevent its adoption by many laboratories. However, the capital costs might be circumvented by having samples analyzed at centralized facilities, as exist for DNA sequencing at many universities.

The current paper is the first report on the use of pyrosequencing to monitor compositions of fungal communities in a plant pathology application. Frequencies of specific SNPs within pools of DNA extracted from crop washings, are reliably detected within the complex communities of A. flavus associated with commercial cotton crops. Reliability of the assays was demonstrated with mixtures of pure DNA and fungal spores and by ground-proofing against VCA performed on the same commercial crop samples (Fig. 1). In tests during the current study, variability among assays attributable to pyrosequencing was less than that attributable to pipetting error. Quantitative information on compositions and temporal shifts of microbial communities is germane to the solution of many problems in the epidemiology and management of plant diseases. Specificity of the current assays for DNA from aflatoxin-producing fungi and to A. flavus is achieved by designing assays for variation in the aflatoxin biosynthesis gene cluster. Complete cluster sequences (66 to $70 \mathrm{~kb}$ ) are available for four isolates of A. flavus as well as A. parasiticus, A. nomius, and an unnamed taxon from West Africa (18). Similar rational approaches might be pursued for the development

TABLE 4. Influence of DNA template quantity on the percent Aspergillus flavus AF36 detected by the aflR assay

\begin{tabular}{|c|c|c|c|c|c|c|c|c|c|}
\hline \multirow[b]{2}{*}{ DNA used (ng) } & \multicolumn{2}{|c|}{ Test 1 (90\% AF36 DNA) } & \multicolumn{2}{|c|}{ Test 2 (60\% AF36 DNA) } & \multicolumn{2}{|c|}{ Test 3 (50\% AF36 DNA) } & \multicolumn{2}{|c|}{ Test 4 (30\% AF36 DNA) } & \multirow[b]{2}{*}{ Mean of $\mathrm{SD}^{\mathrm{z}}$} \\
\hline & Mean ${ }^{\mathrm{y}}$ & SD & Mean ${ }^{y}$ & SD & Mean $^{y}$ & SD & Mean ${ }^{y}$ & SD & \\
\hline 150 & 83.9 & 2.0 & 45.5 & 1.1 & 39.7 & 1.7 & 20.6 & 0.85 & $1.41 \mathrm{c}$ \\
\hline 15 & 83.0 & 1.8 & 43.3 & 1.1 & 38.9 & 2.3 & 20.9 & 0.54 & $1.44 \mathrm{c}$ \\
\hline 1.5 & 81.6 & 2.2 & 44.0 & 1.0 & 36.0 & 1.8 & 19.1 & 0.85 & $1.46 \mathrm{c}$ \\
\hline 0.15 & 81.2 & 1.9 & 41.7 & 1.5 & 36.0 & 5.4 & 17.8 & 0.58 & $2.34 \mathrm{c}$ \\
\hline 0.015 & 85.4 & 5.2 & 41.6 & 1.1 & 29.8 & 7.7 & 17.2 & 1.5 & $3.88 \mathrm{bc}$ \\
\hline 0.0015 & 72.7 & 10.2 & 52.7 & 26.3 & 50.2 & 7.0 & 20.9 & 11.4 & $13.73 \mathrm{~b}$ \\
\hline 0.0003 & 56.6 & 51.3 & 19.6 & 33.9 & 50.0 & 57.7 & 10.2 & 17.6 & $40.13 \mathrm{a}$ \\
\hline 0.00006 & & & & & & & 33.3 & 57.7 & \\
\hline
\end{tabular}

y Mean of four replications.

${ }^{\mathrm{z}}$ Values followed by a common letter are not significantly different as indicated by a least significant difference test at $P=0.05$. SD $=$ standard deviation.

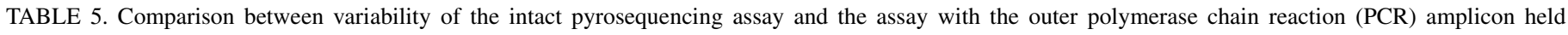
constant using environmental DNA with low quantities of target Aspergillus flavus DNA

\begin{tabular}{|c|c|c|c|c|c|}
\hline \multicolumn{3}{|c|}{ Complete pyrosequencing assay } & \multicolumn{3}{|c|}{ Outer PCR amplicon held constant } \\
\hline Mean $^{y}$ & Range & $\mathrm{SD}$ & Mean ${ }^{y}$ & Range & $\mathrm{SD}$ \\
\hline \multirow[t]{3}{*}{49.0} & $4.9-72.3$ & 38.2 & 1.2 & $0.0-4.9$ & 2.5 \\
\hline & & & 68.8 & $68.0-69.7$ & 0.7 \\
\hline & & & 72.3 & $71.2-72.9$ & 0.7 \\
\hline \multirow[t]{3}{*}{41.4} & $0.0-100.0$ & 52.2 & 0.0 & $0.0-0.0$ & 0.0 \\
\hline & & & 24.3 & $24.1-24.5$ & 0.2 \\
\hline & & & 100.0 & $100.0-100.0$ & 0.0 \\
\hline Average & & $45.2^{z}$ & & & 0.68 \\
\hline
\end{tabular}

y Mean of three replications.

${ }^{\mathrm{z}}$ Average standard deviations (SD) are significantly different $(P<0.01)$ from each other based on a $t$ test of the log to the base 10 transformed data. 
of PAs for many host-pathogen systems in order to monitor specific genotypes of both cultivable pathogens and pathogens that have not yet been cultured. As increased sequence data continues to become available, highly specific assays for most targets will be facilitated and pyrosequencing may become useful for monitoring changes in prevalence among pathogens during any time in the disease cycle.

In haploid organisms, such as the Aspergillus included in the current study, pyrosequencing can be used to monitor virtually any characteristic for which there is a DNA sequence associated. Thus, the frequency of a SNP diagnostic for a phenotype within a pool of DNA from a given source can be used to indicate the proportion of target fungi within that source that exhibit the phenotype in question. In the current study, pyrosequencing was used in this manner. The pksA assay monitors the incidence of a SNP that introduces a stop codon into the DNA encoding the polyketide synthase necessary for aflatoxin biosynthesis and, in so doing, prevents aflatoxin formation (17). As such, this assay directly monitors atoxigenicity. Although there are many mechanisms of atoxigenicity in A. flavus, increasing the incidence of this particular defect in the pksA gene within A. flavus communities is an important goal of biocontrol strategies directed at reducing aflatoxin contamination with $\mathrm{AF} 36$. The $p k s A$ assay monitors atoxigenicity as well as AF36. Critics of the use of atoxigenic strains have concern over potential conversion of AF36 to a toxigenic form. Use of the $p k s A$ assay avoids any potential misinterpretations that might arise if such a conversion occurred because it monitors the specific atoxigenicity and not the organism per se. AF36 has been used on commercial fields since 1996 and has remained stably atoxigenic throughout its use $(4,15)$.

Atoxigenic strains are endemic constituents of A. flavus communities and VCA have been used since 1989 to monitor the proportion of A. flavus communities composed of biological control strains of A. flavus both prior to and after atoxigenic strain applications $(6,15)$. During over a decade of use (15), VCA has been applied to assess both environmental fate and efficacy of atoxigenic strains. Both industry-supported and public sector laboratories have performed many thousands of VCA following the procedures utilized in the current study (15). However, no previous work tested the reproducibility and precision of analysis of fungal communities associated with crops by VCA. The current study shows that the VCA protocol currently utilized to assess influences of atoxigenic strain applications on the composition of fungal communities is precise and reproducible. Furthermore, the SDs of results from the VCA were independent of the percent AF36 detected within the range studied (23 to 99\%; Table 2).

The current study examines the fungal composition of cottonseed washes in order to assess the incidence of a specific A. flavus strain within $A$. flavus communities associated with that crop. A. flavus readily sporulates upon crop infection and the combination of commercial harvesting and ginning with the washing technique allows pooling of conidia from many infections. This is a result not achievable by isolating from individual seed. However, the washing technique requires pelleting of propagules prior to DNA isolation. $\mathrm{DE}$ and $\mathrm{CaCl}_{2}$ were shown to improve both pelleting and DNA recovery. Additionally, DE formed a visible pellet that facilitated DNA isolation.

PAs performed on mixtures of pure DNA had very low variation (Fig. 1). However, pyrosequencing results for DNA recovered from certain field samples were highly variable. The field PAs reported here utilize a nested PCR protocol and in the case of samples with high variability, the variation was attributed to the first PCR (Table 5). The samples with high variability had relatively low quantities of $A$. flavus and we tested if the high variability might be attributed to low quantities of target $A$. flavus DNA. The SD of the aflR pyrosequencing assay was inversely correlated with the quantity of target DNA in assays of mixtures of purified DNA (Table 4). SDs for assays on target DNA with less than $1.5 \mathrm{pg}$ of DNA were over 25 times greater than for assays with $1.5 \mathrm{ng}$ of target DNA. This creates a practical problem for the application of the PAs. This problem was resolved in two manners. First, when isolation is practical or desirable, the quantity of $A$. flavus propagules in a sample is assayed and the quantity of DNA is adjusted to represent DNA from at least 1,000 colony forming units (CFU). Note, this does not require subculturing and characterization of individuals, and as such, is neither labor intensive nor expensive. Second, when culturing is not practical, each assay is performed two times. If the standard deviation is above 15, the assay is performed two more times. An alternative to this might be the application of an immunological or quantitative PCR technique to quantify the total A. flavus prior to pyrosquencing.

Correlations between the VCA and PA were highly significant for both the aflR and pksA assays (Table 3). However, the correlation coefficients for the 2004 crop were higher than those for the 2003 crop. This is because the 2004 assays were performed multiple times (VCG six times and the PAs 5 to 13 times) and the correlations were performed with means, which removed some of the experimental and sampling error.

The current work demonstrates the utility of pyrosequencing for assessing efficacy of biocontrol treatments with the atoxigenic A. flavus strain AF36. Ultimate usefulness of this technique is dependent on proper experimental design, including pre- and posttreatment analyses and untreated controls. However, these assays have less value in determining the absolute distribution of AF36. This stems partly from the diversity and distribution of $A$. flavus VCGs. It is difficult for PAs to reliably discriminate among frequencies $<2 \%$ and in many fields VCG YV36, the VCG to which AF36 belongs, occurs natively at frequencies below $2 \%$. Furthermore, in order to use pyrosequencing methods as identification tools for VCGs, a thorough knowledge of the distribution of the target SNPs among A. flavus VCGs is needed. A. flavus communities are composed of hundreds, if not thousands, of VCGs with some occurring at frequencies below $0.1 \%(6,24)$. Many VCGs have likely never been detected and, as such, it is unlikely that SNP distribution among all VCGs will ever be catalogued. As a result, the actual distribution among VCGs of SNPs utilized in the current paper to track the biocontrol strain AF36 may never be precisely known. The SNP in the polyketide synthase gene responsible for atoxigenicity does not occur in aflatoxin producing fungi, the target of the biocontrol strategy, and, as such, this SNP has clear utility in assessing efficacy. However, this SNP does occur in certain other atoxigenic VCGs (17), although, many atoxigenic A. flavus have different genetic mechanisms for atoxigenicity (7). The aflR SNP utilized in the current study occurred in 5 of 53 A. flavus VCGs examined (M. K. Das and P. J. Cotty, unpublished data). However, regardless of the distribution of the SNPs among A. flavus VCGs, the current work demonstrates the utility of the PAs to assess changes to A. flavus community structures caused by atoxigenic strain treatments. Overall, the PAs are good candidates for replacement of VCA for monitoring incidences of specific genotypes in complex communities of aflatoxin-producing and closely related fungi.

\section{LITERATURE CITED}

1. Adye, J., and Matales, R. I. 1964. Incorporation of labelled compounds into aflatoxins. Biochem. Biophys. Acta 86:418-420.

2. Ahmadian, A., Gharizadeh, B., Gustafsson, A. C., Sterky, F., Nyren, P., Uhlen, M., and Lundeberg, J. 2000. Single-nucleotide polymorphism analysis by pyrosequencing. Anal. Biochem. 280:103-110.

3. Ahmadian, A., Lundeberg, J., Nyren, P., Uhlen, M., and Ronaghi, M. 2000. Analysis of the p53 tumor suppressor gene by pyrosequencing. Biotechniques 28:140-144, 146-147. 
4. Antilla, L., and Cotty, P. J. 2002. The ARS-ACRPC partnership to control aflatoxin in Arizona cotton: Current status. Mycopathologia 155:64.

5. Bayman, P., and Cotty, P. J. 1991. Improved media for selecting nitratenonutilizing mutants in Aspergillus flavus. Mycologia 83:311-316.

6. Bayman, P., and Cotty, P. J. 1991. Vegetative compatibility and genetic diversity in the Aspergillus flavus population of a single field. Can. J. Bot. 69:1707-1711.

7. Chang, P.-K., Horn, B. W., and Dorner, J. W. 2005. Sequence breakpoints in the aflatoxin biosynthesis gene cluster and flanking regions in nonaflatoxigenic Aspergillus flavus isolates. Fungal Genet. Biol. 42:914-923.

8. Cleveland, T. E., Dowd, P. F., Desjardins, A. E., Bhatnagar, D., and Cotty, P. J. 2003. United States Department of Agriculture-Agricultural Research Service research on pre-harvest prevention of mycotoxins and mycotoxigenic fungi in U.S. crops. Pest Manag. Sci. 59:629-642.

9. Cole, R. J., and Cotty, P. J. 1990. Biocontrol of aflatoxin production by using biocompetitive agents. Pages 62-66 in: A Perspective on Aflatoxin in Field Crops and Animal Food Products in the United States. Agricultural Research Service, Beltsville, MD.

10. Cotty, P. J. 1989. Virulence and cultural characteristics of two Aspergillus flavus strains pathogenic on cotton. Phytopathology 79:808-814.

11. Cotty, P. J. 1990. Effect of atoxigenic strains of Aspergillus flavus on aflatoxin contamination of developing cottonseed. Plant Dis. 74:233-235.

12. Cotty, P. J. 1992. Use of native Aspergillus flavus strains to prevent aflatoxin contamination. United States Patent 5,171,686.

13. Cotty, P. J. 1994. Influence of field application of an atoxigenic strain of Aspergillus flavus on the population of A. flavus infecting cotton bolls and on the aflatoxin content of cottonseed. Phytopathology 84:1270-1277.

14. Cotty, P. J. 1994. Comparison of four media for isolation of Aspergillus flavus group fungi. Mycopathologia 125:157-162.

15. Cotty, P. J. 2006. Biocompetitive exclusion of toxigenic fungi. Pages 179197 in: The Mycotoxin Factbook: Food and Feed Topics. D. Barug, D. Bhatnagar, H. P. van Egmond, J. W. van der Kamp, W. A. van Osenbruggen, and A. Visconti, eds. Wageningen Academic Publishers, Wageningen, the Netherlands.

16. Cove, D. J. 1976. Chlorate toxicity in Aspergillus nidulans: The selection and characterization of chlorate resistant mutants. Heredity 36:191-203.

17. Ehrlich, K. C., and Cotty, P. J. 2004. An isolate of Aspergillus flavus used to reduce aflatoxin contamination in cottonseed has a defective polyketide synthase gene. Appl. Microbiol. Biotechnol. 65:473-478.

18. Ehrlich, K. C., Yu, J., and Cotty, P. J. 2005. Aflatoxin biosynthesis gene clusters and flanking regions. J. Appl. Microbiol. 99:518-527.

19. Fakhrai-Rad, H., Pourmand, N., and Ronaghi, M. 2002. Pyrosequencing: An accurate detection platform for single nucleotide polymorphisms. Hum. Mutat. 19:479-485.
20. Garcia, C. A., Ahmadian, A., Gharizadeh, B., Lundegerg, J., Ronaghi, M., and Nyren, P. 2000. Mutation detection by Pyrosequencing: Sequencing of exons 5 to 8 of the p53 tumour supressor gene. Gene 253:249-257.

21. Gharizadeh, B., Kalantari, M., Garcia, C. A., Johansson, B., and Nyren, P. 2001. Typing of human papillomavirus by pyrosequencing. Lab. Invest. 81:673-679.

22. Gharizadeh, B., Norberg, E., Loffler, J., Jalal, S., Tollemar, J., Einsele, H., Klingspor, L., and Nyren, P. 2004. Identification of medically important fungi by the Pyrosequencing technology. Mycoses 47:29-33.

23. Gong, Y., Hounsa, A., Egal, S., Turner, P. C., Sutcliffe, A. E., Hall, A. J., Cardwell, K., and Wild, C. P. 2004. Postweaning exposure to aflatoxin results in impaired child growth: A longitudinal study in Benin, West Africa. Environ. Health Persp. 112:1334-1338.

24. Horn, B. W., and Greene, R. L. 1995. Vegetative compatibility within populations of Aspergillus flavus, A. parasiticus, and A. tamarii from a peanut field. Mycologia 87:324-332.

25. James, M. J., Lasker, B. A., McNeil, M. M., Shelton, M., Warnock, D. W., and Reiss, E. 2000. Use of repetitive DNA probe to type clinical environmental isolates of Aspergillus flavus from a cluster of cutaneous infections in a neonatal intensive care unit. J. Clin. Microbiol. 38:36123618.

26. McAlpin, C. E., Wicklow, D. T., and Horn, B. W. 2002. DNA fingerprinting analysis of vegetative compatibility groups in Aspergillus flavus from a peanut field in Georgia. Plant Dis. 86:254-258.

27. Monstein, H., Nikpour-Badr, S., and Jonasson, J. 2001. Rapid molecular identification and subtyping of Helicobacter pylori by pyrosequencing of the $16 \mathrm{~S}$ rDNA variable V1 and V3 regions. FEMS Microbiol. Lett. 199:103-107.

28. Nordstrom, T., Gharizadeh, B., Pourmand, N., Nyren, P., and Ronaghi, M. 2001. Method enabling fast partial sequencing of cDNA clones. Anal. Biochem. 292:266-271.

29. Park, D. L., and Stoloff, L. 1989. Aflatoxin control - How a regulatory agency managed risk from an unavoidable natural toxicant in food and feed. Regul. Toxicol. Pharm. 9:109-130.

30. Ronaghi, M., Nygren, M., Lundeberg, J., and Nyren, P. 1999. Analyses of secondary structures in DNA by pyrosequencing. Anal. Biochem. 267:6571.

31. Ronaghi, M., Uhlen, M., and Nyren, P. 1998. A sequencing method based on real-time pyrophosphate. Science 281:363-365.

32. Stoloff, L., van Egmond, H. P., and Park, D. L. 1991. Rationales for the establishment of limits and regulations for mycotoxins. Food Addit. Contam. 8:213-222.

33. Wild, C. P., and Turner, P. C. 2002. The toxicology of aflatoxins as a basis for public health decisions. Mutagenesis 17:471. 